CLINICAL STUDY

\title{
Association between gynecomastia and aromatase (CYP19) polymorphisms
}

\author{
Izabella Czajka-Oraniec $^{1,4}$, Wojciech Zgliczynski ${ }^{1}$, Alina Kurylowicz ${ }^{2}$, Michal Mikula ${ }^{3}$ and Jerzy Ostrowski ${ }^{3}$ \\ ${ }^{1}$ Department of Endocrinology, Medical Center for Postgraduate Education, Bielanski Hospital, 80 Ceglowska Street, 01-809 Warsaw, Poland, \\ ${ }^{2}$ Department of Endocrinology, Medical Research Center, Polish Academy of Sciences, 02-106 Warsaw, Poland, ${ }^{3}$ Department of Gastroenterology, Medical \\ Center for Postgraduate Education and Maria Sklodowska-Curie Memorial Cancer Center and Institute of Oncology, 02-781 Warsaw, Poland and ${ }^{4}$ Prince \\ Henry's Institute of Medical Research, Victoria, 3168 Clayton, Australia
}

(Correspondence should be addressed to I Czajka-Oraniec; Email: iczajka@cmkp.edu.pl)

\begin{abstract}
Objective: Aromatase cytochrome P45019 (CYP19) is a key enzyme in estrogen biosynthesis, and polymorphisms within its gene are associated with an increased risk of estrogen-dependent diseases. Enhanced estrogen stimulation of breast tissue in men may lead to gynecomastia. We assessed whether intron 4 (TTTA) $n$ repeat and TCT deletion/insertion polymorphisms and an exon 10 (3'-UTR) C/T single nucleotide polymorphism of CYP19 are associated with gynecomastia.

Design/methods: We performed a genetic association study of 100 patients referred to the endocrinological outpatient clinic with breast glandular tissue enlargement confirmed by clinical and ultrasound examinations and 99 healthy volunteers without gynecomastia. Microsatellite (TTTA) $n$ and insertion/deletion polymorphisms were studied using capillary electrophoresis, and the C/T polymorphism in the 3'-UTR was analyzed using the TaqMan assay.

Results: Significantly increased risk of gynecomastia was found in subjects carrying a CYP19 exon $10 \mathrm{~T}$ allele that was previously related to the high aromatase activity. Frequency of the TT genotype was significantly higher in patients when compared with controls (40.6 vs $26.3 \%$; TT versus CT and CC genotypes; $\left.P_{\mathrm{c}}<0.05\right)$. We found strong linkage disequilibrium between the alleles of studied polymorphic loci. T allele in the 3'-UTR was in linkage disequilibrium with the long alleles of the intron 4 polymorphism, mainly (TTTA)11. However, our findings did not show significant correlation of alleles having more than nine TTTA repeats with gynecomastia.

Conclusions: The CYP19 polymorphisms might contribute to the incidence of gynecomastia, but further studies in larger groups are needed to confirm these results.
\end{abstract}

European Journal of Endocrinology 158 721-727

\section{Introduction}

Gynecomastia is a benign enlargement of the male breast due to glandular tissue proliferation, occurring in approximately one-third of adult men, with even higher rates in pubertal boys and aging males (1). It results from an imbalance in estrogen and androgen action at the breast tissue level (2). Aromatase (CYP19) activity is important in maintaining this balance. This cytochrome P450 enzyme converts androgens, namely androstenedione and testosterone, to estrone and estradiol respectively. In men, the conversion takes place mainly in extraglandular sites (e.g., skin, adipose tissue, bone) and in cases of gynecomastia, most likely in breast stromal cells (3).

The genetic background of this condition remains largely unknown though it is highly probable. Prevalence of gynecomastia varies among different ethnic groups (4) or men sharing the same risk factors (5). Transgenic male mice overexpressing human P450 aromatase were found to develop enlarged mammary glands (6), and recent investigations showed that gainof-function mutations in aromatase gene (CYP19) in men may be responsible for the increased aromatase activity resulting in hyperestrogenism and gynecomastia inherited as a familial trait (7). Gynecomastia can also occur in men with no hormonal changes but enhanced estrogen biosynthesis at the breast tissue level (8). Breast enlargement for unknown reasons, or idiopathic gynecomastia, is present in up to $50 \%$ of patients (9).

More than 80 CYP19 polymorphisms have been described (10). Of these, the most extensively studied are the intron 4 short tandem repeat tetranucleotide (TTTA) $n$ and TCT insertion/deletion (TCT I/D) polymorphisms located 50 bp upstream of the (TTTA) $n$ repeat. Variant alleles and genotypes of both polymorphisms are associated with the risk of estrogen-dependent diseases, including breast (11-15), endometrial cancers (16), endometriosis (17), or osteoporosis (18-21). 
The common single nucleotide polymorphism (SNP) $\mathrm{C} / \mathrm{T}$ (rs10046) in the exon $103^{\prime}$-UTR is associated with osteoporosis (21), breast cancer (22), and sex hormone levels in postmenopausal women (11). The T allele of this SNP is related to a high aromatase activity phenotype (22).

We conducted a genetic association study to determine the potential relationship between these intron 4 and exon 10 polymorphisms and the incidence of gynecomastia.

\section{Materials and methods}

\section{Studied groups}

The patient participants were recruited from referrals to the endocrinological outpatient clinic between 2004 and 2006 presenting breast enlargement and/or tenderness as the main symptoms. Diagnosis of gynecomastia was based on physical and ultrasound (US) examination. It was defined as a palpable uni- or bilateral mobile button of firm subareolar breast tissue at least $2 \mathrm{~cm}$ in diameter or larger female-like breast (23). At US, either homogenous hypoechoic breast glandular tissue was present beneath the nipple or more non-homogenous and hyperechogenic glandular tissues were found together with the increased amount of adipose and fibrous tissue, appearance similar to that noted in female dysplastic breast (24). Following examination, 6 men were excluded because diagnosis of lipomastia was established and 100 patients were finally included. Median age at presentation was 26.0 years (interquartile, IQ range 21.0-48.0), and the mean duration of the symptoms was $4.5 \pm 5.5$ years. A control group was composed of 99 healthy volunteers recruited from hospital staff, medical, and police academy students, who had no palpable breast tissue present at the clinical examination and claimed not to have had breast enlargement or pain in the past as well. Their median age was 22.0 years (IQ range 21.0-29.0). All patients and controls were Polish Caucasians.

The local ethics committee approved the study and all participants provided informed consent. Patients submitted a detailed medical history and underwent a physical examination and blood sampling for hormonal tests and genotyping assays. Serum hormone levels were analyzed to elucidate the possible causes of gynecomastia. Testosterone, estradiol, and luteinizing hormone (LH) levels were measured in all cases, and prolactin (PRL), follicle-stimulating hormone (FSH), DHEA-S, and thyrotropin (TSH) were assayed in selected cases. Measurements of estradiol, FSH, LH, and TSH were performed using the Immulite 2000 chemiluminescence assay systems (Diagnostic Products Corporation, Siemans Healthcare Diagnostics, Deerfield, IL, USA). The sensitivity limit for estradiol was $20.0 \mathrm{pg} / \mathrm{ml}$. Testosterone and DHEA-S were measured using commercial RIA kits (TESTO-CT2 Kit, CIS Bio International, Bagnols/ Ceze, France and Spectria DHEAS RIA kit, Orion Diagnostica, Espoo, Finland), whereas PRL levels were determined by immunoradiometric assay (RIA-gnost PROL, CIS Bio International). Body mass index (BMI) was calculated as the ratio between weight and square of the height (in $\mathrm{kg} / \mathrm{m}^{2}$ ).

\section{Genetic analysis}

Genomic DNA was extracted from whole blood treated with EDTA using the NucleoSpin Blood Quick Pure kit (Macherey-Nagel GmbH \& Co. KG, Düren, Germany), following the manufacturer's protocol. For detection of the tetranucleotide (TTTA) $n$ polymorphism and TCT I/D polymorphism in intron 4 of CYP19, the region of interest containing both polymorphic sites was amplified using PCR, with previously described primers (25): forward 5'-GCAGGTACTTAGTTAGCTAC- $3^{\prime}$ and reverse 5'-TTACAGTGAGCCAAGGTCGT-3'. The forward primer was $5^{\prime}$ end labeled with a fluorescent dye FAM for the automated fragment analysis. The reaction was carried out in $25 \mu \mathrm{l}$ volumes containing $40 \mathrm{ng}$ genomic DNA, $200 \mu \mathrm{M}$ dNTPs, $1.25 \mathrm{U}$ Taq polymerase (AmpliTaq Gold DNA Polymerase, Applied Biosystems, Foster City, CA, USA), $0.5 \mu \mathrm{M}$ of the above-described primers, $1.5 \mathrm{mM}$ $\mathrm{MgCl}_{2}, 2.5 \mu \mathrm{l}$ GeneAmp PCR Buffer II, and distilled water. After preincubation at $95^{\circ} \mathrm{C}$ for $10 \mathrm{~min}$, the PCR amplification was performed for 40 cycles of $94{ }^{\circ} \mathrm{C}$ for $30 \mathrm{~s}, 58^{\circ} \mathrm{C}$ for $45 \mathrm{~s}$, and $72^{\circ} \mathrm{C}$ for $1 \mathrm{~min}$, followed by a final incubation at $72{ }^{\circ} \mathrm{C}$ for 4 min on the GeneAmp PCR System 9700 (Applied Biosystems). Fluorescently labeled PCR products $(0.5 \mu \mathrm{l}$ of the post-reaction mix $)$ were added to the mixture of formamide $(8 \mu \mathrm{l})$ and $0.3 \mu \mathrm{l}$ of the GeneScan-500 ROX size standard (Applied Biosystems), heated for $3 \mathrm{~min}$ at $95^{\circ} \mathrm{C}$, quenched in an ice bath, and then analyzed by size with automated capillary electrophoresis on the ABI PRISM 3100 Genetic Analyzer (Applied Biosystems) and determined using GeneScan 3.7 software (Applied Biosystems).

A few samples with the frequent alleles $(168,171$, and $187 \mathrm{bp}$ ) were sequenced by a dye terminator method on the ABI PRISM 3100 Genetic Analyzer to confirm their TTTA repeat number status and the presence or absence of the TCT deletion and to define other product sizes (results not shown).

Genotyping of the 3'-UTR C/T (rs10046) polymorphism was carried out using TaqMan SNP Genotyping Assays (Applied Biosystems): C_8234731_1_. The PCRs were performed in 96-well plates on the ABI PRISM 7000 Sequence Detection System (SDS; Applied Biosystems). Each well contained 40 ng genomic DNA, $1.25 \mu \mathrm{l}$ TaqMan SNP Genotyping Assay (probes and primers mix), $12.5 \mu \mathrm{l}$ TaqMan Universal PCR Master Mix, No AmpErase UNG (Applied Biosystems), and $9.25 \mu \mathrm{l}$ water. Two control wells with no DNA template were included in each plate. After DNA amplification $\left(95^{\circ} \mathrm{C}\right.$ for $10 \mathrm{~min}$, followed by 30 cycles of $92^{\circ} \mathrm{C}$ for $15 \mathrm{~s}$ 
and $60{ }^{\circ} \mathrm{C}$ for $\left.1 \mathrm{~min}\right)$, fluorescence was detected by SDS and analyzed by the ABI Prism SDS v. 1.1 software for allelic discrimination.

Genotypes for $3^{\prime}$-UTR C/T SNP were obtained for 190 participants (95.5\%); (TTTA) $n$ and I/D TCT polymorphisms were obtained for 198 (99.5\%).

\section{Statistical analysis}

The results for continuous variables are given as medians and quartiles because all variables showed non-normal distribution. Non-parametric Kruskal-Wallis and Mann-Whitney $U$ tests were used to compare groups. The results for discrete variables are shown in frequency tables. The frequency distribution of alleles, genotypes, and haplotypes was compared using standard or Yatescorrected $\chi^{2}$-tests and Fisher's exact test when appropriate. $P$ values were Bonferroni corrected for multiple testing of two polymorphisms ( $P$ multiplied by 2 ) or tests in subgroups ( $P$ multiplied by 3$)$. Corrected value $P_{\mathrm{c}}<0.05$ was considered significant. STATISTICA 6.0 software (Stat Soft Inc, Tulsa, OK, USA) was used. Odds ratios (ORs) with 95\% confidence intervals (CI) were calculated using the calculator available at http://www. hutchon.net/ConfidOR.htm. Linkage disequilibrium (LD) analysis and calculation of the Hardy-Weinberg equilibrium were done by Genepop v. 3.4, available at http://genepop.curtin.edu.au/ (26).

\section{Results}

Medical histories and hormonal analysis results showed that all patients could be divided into two groups: patients with idiopathic gynecomastia who were otherwise healthy with hormone levels in normal ranges and no history of taking gynecomastia-inducing substances $(n=44$, median age 25.0 years; IQ range 20.0-34.5), and patients with breast enlargement associated with other conditions, hormonal disorders (e.g., hypogonadism, hyperprolactinemia, or hyperestrogenism), or drug-induced $(n=56$, median age 30.0 years; IQ range 22.0-61.0). Group characteristics are shown in Table 1.

Significant differences were detected between pooled gynecomastia cases and controls in age (medians: $26.0 \mathrm{vs}$ 22.0 years; $\left.P_{\mathrm{c}}<0.05\right)$, BMI $\left(26.3\right.$ vs $23.7 \mathrm{~kg} / \mathrm{m}^{2} ; P_{\mathrm{c}}<$ $0.05)$, and the levels of LH (3.8 vs $\left.2.6 \mathrm{U} / \mathrm{l} ; P_{\mathrm{c}}<0.05\right)$ and testosterone $\left(4.6\right.$ vs $\left.5.5 \mathrm{ng} / \mathrm{ml} ; P_{\mathrm{c}}<0.05\right)$. However, patients with idiopathic gynecomastia did not differ from controls, and presented results arose from the differences between the secondary gynecomastia group and the healthy control subjects. Although the median values of detected estradiol levels did not differ among both gynecomastia groups and the control group (24.5, 25.3 , and $27.1 \mathrm{pg} / \mathrm{ml}$ respectively; $P=\mathrm{NS}$ ), the percentage of estradiol measurements below the sensitivity limit was lower in all patients groups than in controls (43.2 and $50.0 \%$ compared with $70.7 \%$ respectively; $\left.P_{c}<0.05\right)$.

In the analysis of intron 4 polymorphisms, we detected nine different PCR products. We correlated the microsatellite band sizes with TTTA repeat number by sequencing a few samples. The shortest allele of 168 bp carried seven TTTA repeats and a 3 bp deletion $50 \mathrm{bp}$ upstream of the repetitive sequence, and we identified it as (TTTA)7+delTCT; the allele of $171 \mathrm{bp}$ had the same number of TTTA repeats but no TCT deletion, so we defined it as (TTTA)7. The next most-

Table 1 Characteristic of the studied populations.

\begin{tabular}{|c|c|c|c|c|}
\hline \multirow[b]{2}{*}{ Parameter } & \multicolumn{3}{|c|}{ Gynecomastia } & \multirow[b]{2}{*}{ Controls } \\
\hline & All cases & Idiopathic cases & Other cases & \\
\hline Age (years) & 26.0 & 25.0 & $\begin{array}{l}30.0 \\
2 ? 0-610^{\ddagger}(n=56)\end{array}$ & 22.0 \\
\hline BMI $\left(\mathrm{kg} / \mathrm{m}^{2}\right)$ & $23.2-29.7^{\star}(n=100)$ & $\begin{array}{l}20.0-34.5(n=44) \\
25.0 \\
22.5-28.9(n=44)\end{array}$ & $\begin{array}{l}28.0 \\
24.5-31.2^{\ddagger}(n=56)\end{array}$ & $\begin{array}{l}23.7 \\
22.6-26.6(n=99)\end{array}$ \\
\hline Testosterone (ng/ml) & $\begin{array}{l}4.6 \\
2.7-6.0^{*}(n=100)\end{array}$ & $\begin{array}{l}5.6 \\
4.6-6.2(n=44)\end{array}$ & $\begin{array}{l}3.0 \\
2.0-5.2^{\ddagger}(n=56)\end{array}$ & $\begin{array}{l}5.5 \\
4.6-6.7(n=99)\end{array}$ \\
\hline $\mathrm{LH}(\mathrm{U} / \mathrm{l})$ & $\begin{array}{l}3.8 \\
2.1-5.3^{*}(n=100)\end{array}$ & $\begin{array}{l}3.8 \\
2.5-4.5(n=44)\end{array}$ & $\begin{array}{l}3.8 \\
1.8-6.6^{\ddagger}(n=56)\end{array}$ & $\begin{array}{l}2.6 \\
1.8-4.2(n=99)\end{array}$ \\
\hline $\mathrm{FSH}(\mathrm{U} / \mathrm{l})$ & $\begin{array}{l}3.9 \\
2.3-6.6(n=84)\end{array}$ & $\begin{array}{l}4.3 \\
3.1-6.8(n=34)\end{array}$ & $\begin{array}{l}3.6 \\
1.8-6.6(n=50)\end{array}$ & $\begin{array}{l}3.9 \\
3.0-5.5(n=38)\end{array}$ \\
\hline Estradiol > 20 pg/ml (pg/ml) & $\begin{array}{l}24.8 \\
22.6-29.2(n=53)\end{array}$ & $\begin{array}{l}24.5 \\
22.6-28.2(n=25)\end{array}$ & $\begin{array}{l}25.3 \\
22.4-29.8(n=28)\end{array}$ & $\begin{array}{l}27.1 \\
23.7-33.7(n=29)\end{array}$ \\
\hline $\begin{array}{l}\text { Estradiol <20 pg/ml (\%) } \\
\text { PRL }(\mu \mathrm{g} / \mathrm{l})\end{array}$ & $\begin{array}{l}47.0^{\star} \\
6.0 \\
4.5-11.0(n=77)\end{array}$ & $\begin{array}{l}43.2^{\dagger} \\
5.5 \\
3.5-10.0(n=33)\end{array}$ & $\begin{array}{l}50.5^{\ddagger} \\
7.0 \\
4.8-12.5(n=44)\end{array}$ & $\begin{array}{l}70.7 \\
6.5 \\
5.0-9.0(n=38)\end{array}$ \\
\hline DHEA-S (nmol/l) & $\begin{array}{l}2710 \\
1465-3746(n=71)\end{array}$ & $\begin{array}{l}3039 \\
2133-4043(n=28)\end{array}$ & $\begin{array}{l}2457 \\
1111-3737^{\ddagger}(n=43)\end{array}$ & $\begin{array}{l}3263 \\
2555-4310(n=91)\end{array}$ \\
\hline TSH $(\mu \mathrm{IU} / \mathrm{I})$ & $\begin{array}{l}1.4 \\
0.9-2.0(n=74)\end{array}$ & $\begin{array}{l}1.5 \\
1.0-1.9(n=31)\end{array}$ & $\begin{array}{l}1.2 \\
0.7-2.2(n=43)\end{array}$ & $\begin{array}{l}1.0 \\
0.8-1.5(n=41)\end{array}$ \\
\hline
\end{tabular}

Data are given as medians and interquartile ranges. ${ }^{\star} P<0.05$ all cases compared with controls; ${ }^{\dagger} P<0.05$ idiopathic cases compared with controls; ${ }^{\ddagger} P<0.05$ other cases compared with controls. 
frequent allele of $187 \mathrm{bp}$ had 11 TTTA repeats and a TCT insertion and we defined it as (TTTA)11. Alleles of $172 \mathrm{bp}$ (TTTA) $8+$ delTCT, $175 \mathrm{bp}$ (TTTA)8, $179 \mathrm{bp}$ (TTTA)9, $183 \mathrm{bp}$ (TTTA)10, $191 \mathrm{bp}$ (TTTA)12, and 195 bp (TTTA) 13 were found rarely. Table 2 gives the frequencies of each allele.

Genotyping CYP19 polymorphism data from controls (Table 2) revealed that genotype frequencies were in Hardy-Weinberg equilibrium $(P>0.05)$. The observed CYP19 alleles distribution is similar to those reported in other Caucasian male populations $(10,12,14,16,19)$.

Based on the results from previous reports, we checked for association of the intron 4 'long alleles', having more than nine TTTA repeats and T allele in 3'-UTR with gynecomastia. Although we did not find the significant differences in frequency of the 'short' and 'long' alleles between patients and controls, we have noticed that the shortest allele of $168 \mathrm{bp}$ (TTTA) $7+$ delTCT was insignificantly less frequent in patients with gynecomastia (24.0 vs $\left.33.2 \% ; P_{\mathrm{c}}=0.08\right)$. The frequency of this allele was similar in patients with idiopathic gynecomastia (20.5\%) and secondary gynecomastia (26.8\%).

Table 3 shows the distribution of CYP19 intron 4 genotypes. Only genotype found in at least ten participants were shown. It was previously showed that (TTTA)11/(TTTA)11 genotype can be associated with higher aromatase activity. Therefore, we tested the hypothesis that this genotype is correlated with gynecomastia. Indeed, its frequency was higher in all cases when compared with controls. However, after applying Bonferroni correction, this difference appeared to be not significant ( 11.0 vs $\left.3.0 \% ; P_{c}=0.06\right)$, although the presence of this genotype was associated with almost a fourfold higher risk for incidence of gynecomastia $(\mathrm{OR}=$ 3.96 ; $95 \% \mathrm{CI}=1.1-14.6$ ).

A significant association was observed between the CYP19 3'-UTR C/T polymorphism and the incidence of

Table 2 Allele distribution of the intronic CYP19 polymorphisms in gynecomastia cases and controls: number of alleles (allele frequency).

\begin{tabular}{|c|c|c|c|}
\hline Allele & Length (bp) & $\begin{array}{c}\text { Gynecomastia } \\
\text { patients } \\
(n=200)\end{array}$ & $\begin{array}{c}\text { Control group } \\
\quad(n=196)\end{array}$ \\
\hline $\begin{array}{l}\text { Short alleles } \\
\text { (TTTA) } n \leq 9\end{array}$ & $168-179$ & $113(56.5)$ & $116(59.2)$ \\
\hline $\begin{array}{l}\text { (TTTA) } 7+ \\
\text { delTCT }\end{array}$ & 168 & $48(24.0)$ & $65(33.2)$ \\
\hline (TTTA)7 & 171 & $28(14.0)$ & $22(11.2)$ \\
\hline $\begin{array}{l}\text { (TTTA) } 8+ \\
\text { delTCT }\end{array}$ & 172 & 0 & $1(0.01)$ \\
\hline (TTTA)8 & 175 & $36(18.0)$ & $28(14.3)$ \\
\hline (TTTA) 9 & 179 & $1(0.5)$ & 0 \\
\hline $\begin{array}{l}\text { Long alleles } \\
(\text { TTTA) } n>9\end{array}$ & $183-195$ & $87(43.5)$ & $80(40.8)$ \\
\hline (TTTA) 10 & 183 & $6(3.0)$ & $6(3.1)$ \\
\hline (TTTA) 11 & 187 & 74 (37.0) & $62(31.6)$ \\
\hline (TTTA) 12 & 191 & $6(3.0)$ & $10(5.1)$ \\
\hline (TTTA)13 & 195 & $1(0.5)$ & $2(1.0)$ \\
\hline
\end{tabular}

Table 3 Distribution of the most frequent CYP19 genotypes in intron 4 in gynecomastia cases and controls: number of genotypes (genotype frequency).

\begin{tabular}{lcc}
\hline $\begin{array}{l}\text { Genotype (TTTA) } \\
\text { and TCT I/D }\end{array}$ & $\begin{array}{c}\text { Gynecomastia } \\
\text { patients }\end{array}$ & Control group \\
\hline 7 delTCT/7 delTCT & $2(2.0)$ & $8(8.1)$ \\
7 delTCT/7 & $9(9.0)$ & $8(8.1)$ \\
7 delTCT/8 & $10(10.0)$ & $8(8.1)$ \\
7 delTCT/11 & $21(21.0)$ & $28(28.3)$ \\
$7 / 11$ & $10(10.0)$ & $8(8.1)$ \\
$8 / 11$ & $14(14.0)$ & $13(13.1)$ \\
$10 / 11$ & $6(6.0)$ & $5(5.1)$ \\
$11 / 11$ & $11(11.0)$ & $3(3.0)$ \\
Total (percent of all & $83(83.0)$ & $81(81.8)$ \\
genotypes) & & \\
\hline
\end{tabular}

gynecomastia (Table 4). The frequency of the T allele was significantly higher in patients when compared with controls (65.4 vs $\left.54.0 \% ; P_{\mathrm{c}}<0.05\right)$. Similar percentage of carriers of $\mathrm{T}$ allele was observed in both specified subgroups of patients, with idiopathic and secondary gynecomastia (66.7 and $64.4 \%$ respectively). We also found that the frequency of the TT genotype was significantly higher in patients when compared with controls (40.6 vs $26.3 \%$; TT versus CT and CC genotypes; $\left.P_{\mathrm{c}}<0.05\right)$. Individuals with the T allele showed a 1.5 -fold higher risk of developing gynecomastia $(\mathrm{OR}=1.6,95 \%$ $\mathrm{CI}=1.1-2.4$ ), while those with the TT genotype had more than double the risk $(\mathrm{OR}=2.03,95 \% \mathrm{CI}=1.1-3.8)$.

The alleles of all studied polymorphic loci showed strong linkage disequilibrium $(P<0.001)$. The TCT I/D polymorphism was in almost complete linkage disequilibrium with a (TTTA) repeat polymorphism, as described previously (27). The presence of the deletion was associated with seven TTTA repeats in all cases but one who carried an allele containing the TCT deletion and eight TTTA repeats. We also confirmed a strong linkage disequilibrium between long alleles of the (TTTA) $n$ polymorphism and the T allele of $3^{\prime}$-UTR SNP. The shortest (TTTA) $n$ allele containing seven repeats was significantly more common in individuals with the C allele of $3^{\prime}$-UTR SNP.

Table 4 Frequency of CYP19 $3^{\prime}$-UTR C/T genotypes and alleles in the studied populations: number of genotypes and alleles (frequency).

\begin{tabular}{lccc}
\hline & $\begin{array}{c}\text { Gynecomastia } \\
\text { patients } \\
(n=182)\end{array}$ & $\begin{array}{c}\text { Control } \\
\text { group } \\
(n=198)\end{array}$ & $\boldsymbol{P}_{\mathbf{c}}$ \\
Allele & $63(34.6)$ & $91(46.0)$ & 0.04 \\
\hline C & $119(65.4)$ & $107(54.0)$ & \\
T & $(n=91)$ & $(n=99)$ & $P_{\mathrm{c}}$ \\
Genotype & $37(40.6)$ & $25(26.3)$ & 0.04 \\
TT & $54(59.4)$ & $74(73.7)$ & \\
CT+CC & & & \\
\hline
\end{tabular}




\section{Discussion}

In this work, we found that $3^{\prime}$-UTR C/T polymorphism in aromatase gene was associated with gynecomastia. Men carrying the $\mathrm{T}$ allele had an increased risk of breast enlargement and $3^{\prime}$-UTR TT genotype was associated with a higher incidence of gynecomastia.

To our knowledge, this study is the first to examine a possible relationship between CYP19 polymorphisms and gynecomastia. Previously, we found an association between an estrogen receptor $\alpha$ gene polymorphism and the incidence of gynecomastia (28, unpublished observations).

In several linkage analyses, other authors have pointed to a microsatellite polymorphism (TTTA) in intron 4 of the CYP19 gene as being a genetic marker that co-segregates with gynecomastia in men and macromastia in women $(29,30)$, confirming the importance of the aromatase gene in the development of gynecomastia. Stratakis et al. noted the presence of the CYP19 (TTTA) 11 allele in all members of a family who had symptoms of enhanced aromatase activity (30). Here, we found that the allele containing 11 TTTA repeats was also more prevalent in patients, and men with two (TTTA)11 alleles had an almost fourfold increased risk of gynecomastia, although these results were not significant after Bonferroni correction. Thus, lack of statistical significance of this association may reflect the relatively weak impact of this polymorphism on gynecomastia development, and consequently, it would require a larger scale population studies to be detectable.

Most of the studies examining the role of the intron 4 CYP19 polymorphisms in breast cancer reported an association with greater numbers of TTTA repeats, ten and more, and disease (11-15), although some other found no association at all (31). Results from the studies on osteoporosis are more straightforward. The association between 'long alleles' having at least 9 (18) or 11 (19) TTTA repeats and higher BMD was found in elderly men and postmenopausal women. On the other hand, the (TTTA) 7 allele was related to the highest bone loss and an increased risk of fractures (20). The alleles containing 11 and 12 TTTA repeats were over-represented in the endometrial cancer patients (16), and the risk of endometriosis was higher in (TTTA)10 allele carriers (17).

In vitro studies provide a connection between the presence of more repeats and enhanced aromatase activity $(16,18)$. Berstein et al. noted an increased estrogen biosynthesis (the highest aromatase activity) in endometrial tumors from (TTTA)11/(TTTA) 11 and (TTTA)11/(TTTA) 12 genotype carriers (16). The results are compatible with those reported by Gennari et al. in skin fibroblasts (18).

Some studies also confirmed the association between polymorphisms in the intron 4 and hormonal status, which could be the result of aromatase activity changes $(12,32,33)$. In postmenopausal women, the alleles
(TTTA) 7 and (TTTA) $7+$ delTCT were significantly associated with lower concentrations of estrone, estrone sulfate, and estradiol $(12,32)$, as well as with higher free testosterone level (33).

Our findings relating CYP19 polymorphisms in intron 4 with gynecomastia showed a lack of significant correlation of long alleles having more than nine TTTA repeats and gynecomastia. However, the shortest allele, which could be associated with decreased aromatase activity, was under-represented in patients with gynecomastia, although not to significance.

In our study, we looked for a possible correlation between CYP19 alleles and genotypes and hormone concentrations, but found none (data not shown). However, we did not assay all possible substrates and products of aromatase (e.g., estrone or androstenedione). Furthermore, the estradiol assay mainly recognized over-range values, and its low sensitivity resulted in a high prevalence of imprecisely determined estradiol concentrations.

The SNP located in exon 10 of CYP19 has received less research focus. Kristensen et al. described a significant association between the presence of the T allele and the TT genotype, breast cancer, and so-called 'high activity' phenotype. In vitro studies showed that the T allele was associated with higher aromatase mRNA levels in breast tumors (22). The results are consistent with those of Dunning et al. (11) and Riancho et al. (21), who identified significantly higher estrogen levels in postmenopausal women with the Tallele. Additionally, women with the TT genotype were less susceptible to bone loss and osteoporosis, possibly the result of enhanced aromatase activity (21). In our study, the T allele and TT genotype frequencies were significantly higher in cases compared with controls. We can assume that in men with gynecomastia, enhanced aromatase activity results in accelerated production of tissue estrogens. However, we did not identify any significant differences in plasma hormone levels between the $\mathrm{T}$ and $\mathrm{C}$ allele carriers.

We demonstrated linkage disequilibrium between intron 4 and exon 10 polymorphisms, confirming the previous findings that long alleles of microsatellite polymorphism in intron 4 , mainly (TTTA) 11 , are in linkage disequilibrium with the T allele in exon 10 (22).

The molecular mechanisms responsible for changes in aromatase activity and susceptibility in estrogendependent diseases are unclear. Although polymorphisms in non-coding areas may affect gene expression, influencing transcription or mRNA stability, the studied polymorphisms in intron 4 do not directly affect aromatase activity and most likely act as molecular markers (18). They are in linkage disequilibrium with a SNP in $3^{\prime}$-UTR of exon 10 and possibly with other functional polymorphisms. Kristensen et al. proposed that 3'-UTR polymorphism may enhance transcription from the more active ovary promoter (instead of the adipose promoter), causing an elevated aromatase mRNA level (22). C-to-T substitution may also result 
in changes in secondary structure that could influence transcript stability or regulate translation termination. Further functional analyses are required to determine how CYP19 polymorphisms could be involved in gynecomastia development.

The major limitation of our study is the relatively low number of participants, which was not sufficient for statistical power in some analyses, especially those of microsatellite polymorphism in intron 4. An advantage of the work, however, is ethnic homogeneity; all participants were Polish Caucasians. In addition, this is the first study addressing an association between CYP19 polymorphisms and gynecomastia. These preliminary results are promising and consistent with the most genetic association studies of CYP19 polymorphisms in estrogen-related diseases.

This study confirmed that gynecomastia is a disorder of complex multifactorial etiology, not only hormonal and environmental but also genetic. The identified association between the CYP19 polymorphisms and the incidence of gynecomastia may provide new ways to identify patients at risk for this condition and suggest that investigations of the effectiveness of aromatase inhibitors for selected patient with gynecomastia may be useful.

\section{Acknowledgements}

This research was supported by the Medical Center for Postgraduate Education grant (501-2-1-08-54/05). M M was supported by the Foundation for Polish Science (START Program).

\section{References}

1 Braunstein GD. Gynecomastia. New England Journal of Medicine 1993328 490-495.

2 Braunstein GD. Aromatase and gynecomastia. Endocrine-Related Cancer 19996 315-324.

3 Simpson ER, Clyne C, Rubin G, Boon WC, Robertson K, Britt K, Speed C \& Jones M. Aromatase - a brief overview. Annual Review of Physiology 200264 93-127.

4 Nydick M, Butos J, Dale JH \& Rawson RW. Gynecomastia in adolescent boys. Journal of the American Medical Association 1961 $178449-454$.

5 Wilson JD \& Roehrborn C. Long-term consequences of castration in men: lessons from the Skoptzy and the eunuchs of the Chinese and Ottoman courts. Journal of Clinical Endocrinology and Metabolism 199984 4324-4331.

6 Li X, Warri A, Makela S, Ahonen T, Streng T, Santti R \& Poutanen M. Mammary gland development in transgenic male mice expressing human P450 aromatase. Endocrinology 2002 143 4074-4083.

7 Shozu M, Sebastian S, Takayama K, Hsu W-T, Schultz RA, Neely K, Bryant M \& Bulun SE. Estrogen excess associated with novel gainof-function mutations affecting the aromatase gene. New England Journal of Medicine $2003 \mathbf{3 4 8} 1855-1865$.

8 Bulard J, Mowszowicz I \& Schaison G. Increased aromatase activity in pubic skin fibroblasts from patients with isolated gynecomastia. Journal of Clinical Endocrinology and Metabolism 1987 64 618-623.
9 Griffin JE \& Wilson JD. Abnormalities in estrogen metabolism. In Williams Textbook of Endocrinology, edn 10, pp 741-746. Eds PR Larsen, HM Kronenberg, S Melmed \& KS Polonsky, Philadelphia: Saunders, 2003.

10 Ma CX, Adjei AA, Salavaggione OE, Coronel J, Pelleymounter L, Wang L, Eckloff BW, Schaid D, Wieben ED, Adjei AA \& Weinshilboum RM. Human aromatase: gene resequencing and functional genomics. Cancer Research 200565 11071-11082.

11 Dunning AM, Dowsett M, Healey CS, Tee L, Luben RN, Folkerd E, Novik KL, Kelemen L, Ogata S, Pharoah PD, Easton DF, Day NE \& Ponder BA. Polymorphisms associated with circulating sex hormone levels in postmenopausal women. Journal of the National Cancer Institute 200496 936-945.

12 Haiman CA, Hankinson SE, Spiegelman D, De Vivo I, Colditz GA, Willett WC, Speizer FE \& Hunter DJ. A tetranucleotide repeat polymorphism in CYP19 and breast cancer risk. International Journal of Cancer 200087 204-210.

13 Han DF, Zhou X, Hu MB, Xie W, Mao ZF, Chen DE, Liu F \& Zheng F. Polymorphisms of estrogen-metabolizing genes and breast cancer risk: a multigenic study. Chinese Medical Journal 2005118 1507-1516.

14 Kristensen VN, Andersen TI, Lindblom A, Erikstein B, Magnus P \& Borresen-Dale AL. A rare CYP19 (aromatase) variant may increase the risk of breast cancer. Pharmacogenetics $1998 \mathbf{8}$ 43-48.

15 Ahsan H, Whittemore AS, Chen Y, Senie RT, Hamilton SP, Wang Q, Gurvich I \& Santella RM. Variants in estrogen-biosynthesis genes CYP17 and CYP19 and breast cancer risk: a family-based genetic association study. Breast Cancer Research 20057 R71-R81.

16 Berstein LM, Imyanitov EN, Kovalevskij AJ, Maximov SJ, Vasilyev DA, Buslov KG, Sokolenko AP, Iyevleva AG, Chekmariova EV \& Thijssen JH. CYP17 and CYP19 genetic polymorphisms in endometrial cancer: association with intratumoral aromatase activity. Cancer Letters 2004207 191-196.

17 Arvanitis DA, Koumantakis GE, Goumenou AG, Matalliotakis IM, Koumantakis EE \& Spandidos DA. CYP1A1, CYP19, and GSTM1 polymorphisms increase the risk of endometriosis. Fertility and Sterility 200379 702-709.

18 Gennari L, Masi L, Merlotti D, Picariello L, Falchetti A, Tanini A, Mavilia C, Del Monte F, Gonnelli S, Lucani B, Gennari C \& Brandi ML. A polymorphic CYP19 TTTA repeat influences aromatase activity and estrogen levels in elderly men: effects on bone metabolism. Journal of Clinical Endocrinology and Metabolism $2004892803-2810$.

19 Masi L, Becherini L, Gennari L, Amedei A, Colli E, Falchetti A, Farci M, Silvestri S, Gonnelli S \& Brandi ML. Polymorphism of the aromatase gene in postmenopausal Italian women: distribution and correlation with bone mass and fracture risk. Journal of Clinical Endocrinology and Metabolism $2001862263-2269$.

20 Van Pottelbergh I, Goemaere S \& Kaufman JM. Bioavailable estriadol and an aromatase gene polymorphism are determinants of bone mineral density changes in men over 70 years of age. Journal of Clinical Endocrinology and Metabolism $2003 \mathbf{8 8} 3075-3081$.

21 Riancho JA, Zarrabeitia MT, Valero C, Sanudo C, Hernandez JL, Amado JA, Zarrabeitia A \& Gonzalez-Macias J. Aromatase gene and osteoporosis: relationship of ten polymorphic loci with bone mineral density. Bone 200536 917-925.

22 Kristensen VN, Harada N, Yoshimura N, Haraldsen E, Lonning PE, Erikstein B, Karesen R, Kristensen T \& Borresen-Dale AL. Genetic variants of CYP19 (aromatase) and breast cancer risk. Oncogene 200019 1329-1333.

23 Niewoehner CB \& Nuttal FQ. Gynecomastia in a hospitalized male population. American Journal of Medicine 198477 633-638.

24 Günhan-Bilgen I, Bozkaya H, Ustün EE \& Memiş A. Male breast disease: clinical, mammographic, and ultrasonographic features. European Journal of Radiology 200243 246-255.

25 Polymeropoulos MH, Xiao H, Rath DS \& Merril CR. Tetranucleotide repeat polymorphism at the human aromatase cytochrome P450 gene (CYP19). Nucleic Acids Research 199119195. 
26 Raymond M \& Rousset F. GENEPOP (version 1.2): population genetics software for exact tests and ecumenicism. Journal of Heredity $199586248-249$.

27 Dick IM, Devine A \& Prince RL. Association of an aromatase TTTA repeat polymorphism with circulating estrogen, bone structure, and biochemistry in older women. American Journal of Physiology. Endocrinology and Metabolism 2005288 E989-E995.

28 Czajka-Oraniec I, Zgliczynski W, Puzianowska-Kuznicka M, Kurylowicz A, Mikula M \& Ostrowski J. Role of c.454-351A/G polymorphism of estrogen receptor alpha gene in genetic predispsition to idiopathic gynecomastia. 5th Conference of the Section for Molecular Endocrinology of Polish Society of Endocrinology, 28-30 March 2007, Poznan, Poland.

29 Binder G, Iliev DI, Dufke A, Wabitsch M, Schweizer R, Ranke MB \& Schmidt M. Dominant transmission of prepubertal gynecomastia due to serum estrone excess: hormonal, biochemical, and genetic analysis in a large kindred. Journal of Clinical Endocrinology and Metabolism 200590 484-492.

30 Stratakis CA, Vottero A, Brodie A, Kirschner LS, DeAtkine D, Lu Q, Yue W, Mitsiades CS, Flor AW \& Chrousos GP. The aromatase excess syndrome is associated with feminization of both sexes and autosomal dominant transmission of aberrant P450 aromatase gene transcription. Journal of Clinical Endocrinology and Metabolism 199883 1348-1357.

31 Thyagarajan B, Brott M, Mink P, Folsom AR, Anderson KE, Oetting WS \& Gross M. CYP1B1 and CYP19 gene polymorphisms and breast cancer incidence: no association in the ARIC study. Cancer Letters 2004207 183-189.

32 Tworoger SS, Chubak J, Aiello EJ, Ulrich CM, Atkinson C, Potter JD, Yasui Y, Stapleton PL, Lampe JW, Farin FM, Stanczyk FZ \& McTiernan A. Association of CYP17, CYP19, CYP1B1, and COMT polymorphisms with serum and urinary sex hormone concentrations in postmenopausal women. Cancer Epidemiology, Biomarkers and Prevention 200413 94-101.

33 Baghaei F, Rosmond R, Westberg L, Hellstrand M, Eriksson E, Holm G \& Bjorntorp P. The CYP19 gene and associations with androgens and abdominal obesity in premenopausal women. Obesity Research 200311 578-585.

Received 13 December 2007

Accepted 13 February 2008 